\title{
Peripheral Blood Flow in the Neonate. 1. Changes in Total, Skin, and Muscle Blood Flow with Gestational and Postnatal Age
}

\author{
PAUL Y. K. WU, ${ }^{(24)}$ W. H. WONG, GONZALO GUERRA, RENALDO MIRANDA, RAMON R. GODOY, \\ BARBARA PRESTON, SARAH SCHOENTGEN, AND NORMAN E. LEVAN \\ The Department of Pediatrics and Medicine (Dermatology), University of Southern California School of Medicine, \\ Los Angeles County-USC Medical Center, Los Angeles, California, USA
}

\begin{abstract}
Summary
Total peripheral blood flow and blood flow through the skin and muscle were measured in the calf with an electrocapacitance plethysmograph with counter pressure in a group of 62 "well" newborn infants (birth weight, $<3500 \mathrm{~g}$ ). Blood pressure in the contralateral leg was measured with an Arteriosonde 1010, and peripheral vascular resistance was calculated as mean blood pressure ( $\mathrm{mm} \mathrm{Hg}$ ) divided by blood flow ( $\mathrm{ml}$ per $100 \mathrm{ml}$ tissue per min). The results show that total peripheral blood flow and blood flow through the skin and muscle correlated inversely with increasing birth weight and gestational age. Postnatally, total blood flow and blood flow through the skin and muscle decreased gradually during the first 7 days of life and in the rest of the neonatal period. Peripheral vascular resistance and resistance in the skin and muscle correlated directly with increasing birth weight and gestational age. Postnatally, peripheral vascular resistance and resistance in the skin and muscle increased during the first 7 days of life and the neonatal period.
\end{abstract}

\section{Speculation}

The lower peripheral vascular resistance and hypervascularity in the skin of immature infants account for higher peripheral blood flow in these infants. The associated increment in peripheral vascular resistance account for the gradual decrement in peripheral blood flow with advancing maturity and postnatal age. Differences in change of total peripheral blood flow and blood flow in the skin and muscle in relation to change in state, environment, and biochemical alterations need to be studied.

The peripheral vascular bed constitutes one of the major "reservoirs" of the body through which blood can be diverted. This reservoir is more significant in the neonates whose surface area is greater in comparison to adults, and whose skin is much more vascularized $(7,17)$. Previous studies in the newborn infants have shown that peripheral circulation can be altered in response to feeding (22), hypoxia and hypovolemia $(3,5,18)$, ischemia (4), respiratory distress syndrome (12), and changes in body temperature $(1,12)$. More recently, peripheral circulation has been shown to undergo considerable changes in newborn term (14) and preterm infants (2l) on exposure to nonionizing radiant energyphototherapy. In addition, Wu et al. (21) demonstrated that the increment in skin blood flow was much greater than in the muscles in neonates on exposure to phototherapy.

Although peripheral blood flow in neonates have been meticulously studied previously $(2,3,6,15)$, little is known from the literature regarding skin and muscle blood flow in neonates. The present study is aimed at delineating the variations in total, skin and muscle blood flow in "well" newborn infants with birth weights $<3500 \mathrm{~g}$.

\section{MATERIALS AND METHODS}

A group of 62 newborn infants with birth weights $<3500 \mathrm{~g}$ who were clinically well were selected for blood flow measurements Total peripheral blood flow and blood flow through the skin and muscle were measured in the calf with an electrocapacitance plethysmograph with local counterpressure as described by Hyman et al. $(9,10)$. Modifications were made in the size of the pressure cuffs in the arterial, venous, and counterpressure system to adapt it for use in the premature infant as described previously by Wu et al. (21). The infants were placed in an incubator with servo control (model, Isolette-C86) to maintain abdominal skin temperature at $36.5^{\circ} \mathrm{C}$. Contralateral calf skin temperature was measured with a Yellow Spring thermometer. Blood flow measurements were made with infant at "rest" 0.5 to $1.5 \mathrm{hr}$ after a feed (21).

Blood pressure in the contralateral leg was measured with an Arteriosonde 1010 Ultrasonic Blood Pressure machine just before the blood flow measurements. Peripheral vascular resistance was expressed in "resistance units" and calculated as mean blood pressure $(\mathrm{mm} \mathrm{Hg})$ divided by blood flow $(\mathrm{ml}$ per $100 \mathrm{ml}$ tissue per min).

Daily measurements were made during the first wk of life. In addition, 18 infants (mean birth weight, $1450.3 \pm 178.9 \mathrm{~g}$; mean gestational age, $32 \pm 1.9 \mathrm{wk}$ ) were followed at weekly intervals to determine changes in blood flow with postnatal age.

\section{STATISTICAL METHODOLOGY}

The data were analyzed on the University of Southern California's IBM 370/158 computer using the Statistical Package for the Social Sciences (13). Statistical analyses were performed to test for significant changes in blood flow and peripheral vascular resistance measurements during increasing postnatal age. Further analyses were done to test for differences among gestational age groups and birth weight groups. One-way analyses of variance were used to test for changes in measurements over the first 7 postnatal days. For the sample of 18 babies who were followed for $4 \mathrm{wk}$, the four weekly means were similarly compared. In addition, Scheffe's pair-wise comparison technique was used to indicate, at an overall alpha of 0.05 , which days (or weeks) were significantly different (16). One-way analyses of variance were also performed to compare the different gestational age and birth weight groups. Finally, regression analyses were utilized to determine the overall correlation between peripheral blood flow and peripheral vascular resistance measurements and postnatal age.

\section{RESULTS}

The differences in total peripheral blood flow and blood flow through the skin and muscle in relation to birth weight and gestational age are shown in Tables 1 and 2, respectively. The 
Table 1. Differences in blood flow ( $\mathrm{ml}$ per $100 \mathrm{ml}$ tissue per min) with birth weight groups during the first 7 postnatal days

\begin{tabular}{|c|c|c|c|c|c|c|c|}
\hline \multirow{2}{*}{$\begin{array}{l}\text { Birth weight } \\
\text { groups }^{1} \mathrm{BF}^{2}\end{array}$} & \multicolumn{7}{|c|}{ Postnatal days } \\
\hline & 1 & 2 & 3 & 4 & 5 & 6 & 7 \\
\hline \multicolumn{8}{|l|}{ Total BF } \\
\hline$A^{3}(3)^{4}$ & $16.8 \pm 0.8^{5}$ & $15.7 \pm 0.7$ & $15.1 \pm 0.6$ & $14.3 \pm 2.2$ & $13.3 \pm 1.8$ & $12.1 \pm 1.9$ & $12.1 \pm 1.6$ \\
\hline B (22) & $14.1 \pm 1.2$ & $12.3 \pm 1.4$ & $12.2 \pm 1.3$ & $11.6 \pm 1.1$ & $11.4 \pm 1.2$ & $11.2 \pm 1.3$ & $10.9 \pm 1.4$ \\
\hline$C(26)$ & $11.6 \pm 2.2$ & $10.6 \pm 1.5$ & $10.4 \pm 1.3$ & $10.5 \pm 1.5$ & $10.2 \pm 1.3$ & $10.2 \pm 1.2$ & $10.0 \pm 1.3$ \\
\hline $\mathrm{D}(11)$ & $9.0 \pm 1.2$ & $8.4 \pm 1.5$ & $8.2 \pm 1.4$ & $8.4 \pm 1.6$ & $8.0 \pm 1.4$ & $8.2 \pm 1.3$ & $8.2 \pm 1.4$ \\
\hline \multicolumn{8}{|l|}{ Skin BF } \\
\hline A & $8.4 \pm 0.4$ & $6.6 \pm 0.7$ & $6.6 \pm 0.6$ & $6.2 \pm 1.0$ & $6.1 \pm 0.8$ & $6.3 \pm 0.8$ & $5.8 \pm 0.8$ \\
\hline B & $6.8 \pm 0.7$ & $5.7 \pm 0.8$ & $5.6 \pm 0.7$ & $5.1 \pm 0.7$ & $5.0 \pm 0.7$ & $5.3 \pm 0.7$ & $4.9 \pm 0.8$ \\
\hline $\mathrm{C}$ & $5.4 \pm 1.2$ & $4.7 \pm 0.7$ & $4.5 \pm 0.7$ & $4.6 \pm 0.8$ & $4.4 \pm 0.8$ & $4.6 \pm 0.7$ & $4.4 \pm 0.7$ \\
\hline D & $3.9 \pm 1.1$ & $3.5 \pm 1.0$ & $3.5 \pm 0.8$ & $3.7 \pm 0.9$ & $3.4 \pm 0.6$ & $3.7 \pm 0.6$ & $3.6 \pm 0.7$ \\
\hline \multicolumn{8}{|l|}{ Muscle BF } \\
\hline A & $8.4 \pm 0.5$ & $8.9 \pm 0.2$ & $8.5 \pm 0.2$ & $7.8 \pm 0.8$ & $7.2 \pm 1.0$ & $6.3 \pm 1.1$ & $6.3 \pm 0.8$ \\
\hline B & $7.3 \pm 0.7$ & $6.7 \pm 1.0$ & $6.6 \pm 0.8$ & $6.5 \pm 0.6$ & $6.4 \pm 0.7$ & $5.9 \pm 0.8$ & $5.9 \pm 0.7$ \\
\hline $\mathrm{C}$ & $6.2 \pm 1.3$ & $5.9 \pm 1.0$ & $6.0 \pm 0.9$ & $5.9 \pm 0.8$ & $5.8 \pm 0.7$ & $5.5 \pm 0.8$ & $5.6 \pm 0.6$ \\
\hline D & $5.1 \pm 1.0$ & $4.9 \pm 0.6$ & $4.8 \pm 0.6$ & $4.8 \pm 0.8$ & $4.6 \pm 0.9$ & $4.5 \pm 0.8$ & $4.6 \pm 0.8$ \\
\hline
\end{tabular}

' Differences between weight groups are significant $(P<0.0001)$.

${ }^{2} \mathrm{BF}$, blood flow.

${ }^{3}$ Group A, <1000 g; group B, 1000 to $1499 \mathrm{~g}$; group C, 1500 to $1999 \mathrm{~g}$; group D, > $2000 \mathrm{~g}$

4 Numbers in parentheses, number of infants.

"Mean \pm 1 S.D.

Table 2. Differences in blood flow ( $\mathrm{ml}$ per $100 \mathrm{ml}$ tissue per min) with gestational age groups during the first 7 postnatal days

\begin{tabular}{|c|c|c|c|c|c|c|c|}
\hline \multirow{2}{*}{$\begin{array}{c}\text { Gestational age } \\
\text { (wks) groups }{ }^{1} \mathrm{BF}^{2}\end{array}$} & \multicolumn{7}{|c|}{ Postnatal days } \\
\hline & 1 & 2 & 3 & 4 & 5 & 6 & 7 \\
\hline \multicolumn{8}{|l|}{ Total BF } \\
\hline$A^{3}(10)^{4}$ & $15.7 \pm 1.3^{5}$ & $14.2 \pm 1.6$ & $13.8 \pm 1.3$ & $12.9 \pm 1.7$ & $12.6 \pm 1.2$ & $12.3 \pm 1.1$ & $11.9 \pm 1.2$ \\
\hline B (20) & $13.5 \pm 0.7$ & $11.7 \pm 1.0$ & $11.7 \pm 1.1$ & $11.4 \pm 1.0$ & $10.9 \pm 1.0$ & $10.8 \pm 1.2$ & $10.5 \pm 1.3$ \\
\hline$C(23)$ & $11.2 \pm 0.3$ & $10.3 \pm 1.6$ & $10.2 \pm 1.4$ & $10.3 \pm 1.5$ & $10.0 \pm 1.4$ & $10.0 \pm 1.3$ & $9.9 \pm 1.4$ \\
\hline $\mathrm{D}(9)$ & $8.3 \pm 0.9$ & $8.0 \pm 0.5$ & $7.9 \pm 0.7$ & $7.8 \pm 0.6$ & $7.6 \pm 0.6$ & $7.8 \pm 0.5$ & $7.6 \pm 0.4$ \\
\hline \multicolumn{8}{|l|}{ Skin BF } \\
\hline $\mathbf{A}$ & $7.7 \pm 0.6$ & $6.4 \pm 0.8$ & $6.2 \pm 0.7$ & $5.8 \pm 0.8$ & $5.7 \pm 0.7$ & $5.8 \pm 0.6$ & $5.5 \pm 0.8$ \\
\hline $\mathbf{B}$ & $6.5 \pm 0.5$ & $5.3 \pm 0.6$ & $5.3 \pm 0.7$ & $5.0 \pm 0.6$ & $4.7 \pm 0.7$ & $5.1 \pm 0.8$ & $4.7 \pm 0.7$ \\
\hline C & $5.1 \pm 0.1$ & $4.6 \pm 0.8$ & $4.4 \pm 0.7$ & $4.5 \pm 0.8$ & $4.4 \pm 0.7$ & $4.5 \pm 0.6$ & $4.4 \pm 0.7$ \\
\hline D & $3.5 \pm 0.5$ & $3.3 \pm 0.4$ & $3.3 \pm 0.4$ & $3.4 \pm 0.4$ & $3.2 \pm 0.2$ & $3.5 \pm 0.4$ & $3.3 \pm 0.4$ \\
\hline \multicolumn{8}{|l|}{ Muscle BF } \\
\hline $\mathbf{A}$ & $8.0 \pm 0.8$ & $7.8 \pm 1.1$ & $7.6 \pm 0.8$ & $7.1 \pm 0.8$ & $6.1 \pm 0.7$ & $6.5 \pm 0.7$ & $6.4 \pm 0.6$ \\
\hline B & $7.0 \pm 0.4$ & $6.4 \pm 0.8$ & $6.4 \pm 0.7$ & $6.5 \pm 0.6$ & $6.2 \pm 0.6$ & $5.7 \pm 0.7$ & $5.8 \pm 0.7$ \\
\hline $\mathrm{C}$ & $6.1 \pm 1.3$ & $5.7 \pm 1.0$ & $5.8 \pm 0.9$ & $5.8 \pm 0.7$ & $5.7 \pm 0.8$ & $5.3 \pm 0.9$ & $5.5 \pm 0.8$ \\
\hline D & $4.8 \pm 0.6$ & $4.7 \pm 0.4$ & $4.7 \pm 0.5$ & $4.4 \pm 0.5$ & $4.4 \pm 0.6$ & $4.3 \pm 0.2$ & $4.3 \pm 0.2$ \\
\hline
\end{tabular}

${ }^{1}$ Differences between gestational age groups are significant $(P<0.0001)$.

${ }^{2} \mathrm{BF}$, blood flow.

${ }^{3}$ Group A, < 29 wk; group B, 30 to 33 wk; group C, 34 to 36 wk; group D, > 37 wk.

${ }^{4}$ Number in parentheses, number of infants.

${ }^{5}$ Mean \pm 1 S.D.

results indicate that total, skin, and muscle blood flow correlated inversely with increasing birth weight and gestational age (coefficient correlation ranging from $r=-0.65$ to -0.75 ). Skin blood flow was found to be equal to or slightly less than muscle blood flow, with muscle blood flow tending to be higher than skin blood flow with advancing birth weight and gestational age.

There was a distinct fall in total peripheral blood flow as well as skin and muscle blood flow from the first to the second postnatal days. Thereafter, there was a gradual decrement in blood flow from the second to the seventh postnatal days so that although the day-to-day variations were not all statistically significant; total peripheral blood flow, skin blood flow, and muscle blood flow were statistically lower on the seventh than on the first day postnatally $(P<0.0001)$.
The differences in total peripheral vascular resistance as well as resistance in the skin (SPVR) and muscle (MPVR) in relation to birthweight and gestational age are shown in Tables 3 and 4 . In contrast to blood flow, peripheral vascular resistance, SPVR, and MPVR was found to be correlated directly with increasing birthweight and gestational age (coefficient correlations ranging from $r=0.64$ to 0.72 ). SPVR was found to be greater than MPVR with advancing birth weight and gestational age.

There was a distinct rise in peripheral vascular resistance as well as in SPVR and MPVR from the first to the second postnatal days. Thereafter, the change in peripheral vascular resistance was gradual and reflects the change in blood flow but in the opposite direction (Fig. 1).

Sequential changes in peripheral blood flow were measured in 
WU ET $A L$.

Table 3. Differences in peripheral vascular resistance with birth weight groups during the first 7 postnatal days

\begin{tabular}{|c|c|c|c|c|c|c|c|}
\hline \multirow{2}{*}{$\begin{array}{c}\text { Birth weight } \\
\text { groups' (g) } \\
(\text { PVR) }\end{array}$} & \multicolumn{7}{|c|}{ Postnatal days } \\
\hline & 1 & 2 & 3 & 4 & 5 & 6 & 7 \\
\hline \multicolumn{8}{|l|}{ Total PVR } \\
\hline$A^{3}(3)^{4}$ & $1.8 \pm 0.2^{5}$ & $2.5 \pm 0.2$ & $2.8 \pm 0.2$ & $3.3 \pm 0.8$ & $3.7 \pm 0.5$ & $4.0 \pm 0.8$ & $4.2 \pm 0.8$ \\
\hline B (22) & $2.6 \pm 0.4$ & $3.7 \pm 0.6$ & $3.7 \pm 0.5$ & $4.2 \pm 0.5$ & $4.4 \pm 0.6$ & $4.7 \pm 0.7$ & $4.8 \pm 0.7$ \\
\hline$C(26)$ & $3.7 \pm 1.1$ & $4.8 \pm 0.8$ & $4.9 \pm 0.7$ & $5.0 \pm 0.9$ & $5.1 \pm 0.8$ & $5.3 \pm 0.7$ & $5.4 \pm 0.8$ \\
\hline $\mathrm{D}(11)$ & $5.1 \pm 0.9$ & $6.2 \pm 0.8$ & $6.3 \pm 0.9$ & $6.4 \pm 1.0$ & $6.7 \pm 1.0$ & $6.6 \pm 0.9$ & $6.7 \pm 0.9$ \\
\hline \multicolumn{8}{|l|}{ Skin PVR } \\
\hline A $(3$ & $3.7 \pm 0.3$ & $5.9 \pm 0.9$ & $6.3 \pm 0.7$ & $7.6 \pm 1.9$ & $8.0 \pm 1.0$ & $8.1 \pm 1.3$ & $8.9 \pm 1.7$ \\
\hline B (22) & $5.3 \pm 0.8$ & $8.1 \pm 1.4$ & $8.2 \pm 1.3$ & $9.7 \pm 1.6$ & $10.1 \pm 1.7$ & $10.0 \pm 1.8$ & $10.8 \pm 2.0$ \\
\hline$C(26)$ & $8.1 \pm 2.7$ & $10.7 \pm 1.8$ & $11.4 \pm 2.0$ & $11.6 \pm 2.5$ & $12.0 \pm 2.4$ & $11.9 \pm 2.0$ & $12.4 \pm 2.3$ \\
\hline $\mathrm{D}(11)$ & $11.9 \pm 2.5$ & $15.2 \pm 2.8$ & $15.1 \pm 2.6$ & $15.0 \pm 2.6$ & $15.8 \pm 2.4$ & $14.8 \pm 2.2$ & $15.1 \pm 2.4$ \\
\hline \multicolumn{8}{|l|}{ Muscle PVR } \\
\hline$A(3)$ & $3.7 \pm 0.4$ & $4.5 \pm 0.2$ & $4.9 \pm 0.1$ & $5.9 \pm 1.1$ & $6.7 \pm 1.0$ & $8.1 \pm 1.9$ & $8.1 \pm 1.4$ \\
\hline B (22) & $4.9 \pm 0.7$ & $6.9 \pm 1.2$ & $7.0 \pm 1.1$ & $7.5 \pm 0.8$ & $7.8 \pm 1.1$ & $8.9 \pm 1.4$ & $8.8 \pm 1.3$ \\
\hline$C(26)$ & $6.9 \pm 2.0$ & $8.7 \pm 1.8$ & $8.6 \pm 1.5$ & $8.8 \pm 1.5$ & $9.0 \pm 1.5$ & $10.0 \pm 1.9$ & $9.7 \pm 1.4$ \\
\hline D (11) & $8.9 \pm 1.5$ & $10.6 \pm 1.2$ & $10.8 \pm 1.3$ & $11.3 \pm 2.0$ & $11.8 \pm 2.3$ & $12.0 \pm 1.6$ & $12.0 \pm 1.6$ \\
\hline
\end{tabular}

${ }^{1}$ Differences between weight groups are significant for each postnatal day $(P<0.0001)$.

${ }^{2}$ Peripheral vascular resistance, $($ PVR $)=\frac{\text { Mean BP } \mathrm{mm} \mathrm{Hg}}{B F \mathrm{ml} / 100 \mathrm{ml} \text { tissue } / \mathrm{min}}$ units.

${ }^{3}$ Group A, < $1000 \mathrm{~g}$; group B, 1000 to 1499 g; group C, 1500 to $1999 \mathrm{~g}$; group D, > $2000 \mathrm{~g}$

${ }^{4}$ Numbers in parentheses, number of infants.

${ }^{5}$ Mean \pm 1 S.D.

Table 4. Differences in peripheral vascular resistance with gestational age groups during the first 7 postnatal days

\begin{tabular}{|c|c|c|c|c|c|c|c|}
\hline \multirow{2}{*}{$\begin{array}{c}\text { Gestational age } \\
\text { groups' (wk) } \\
(\text { PVR) }\end{array}$} & \multicolumn{7}{|c|}{ Postnatal days } \\
\hline & 1 & 2 & 3 & 4 & 5 & 6 & 7 \\
\hline \multicolumn{8}{|l|}{ Total PVR } \\
\hline$A^{3}(10)^{4}$ & $2.1 \pm 0.2^{5}$ & $3.0 \pm 0.4$ & $3.1 \pm 0.4$ & $3.6 \pm 0.5$ & $3.8 \pm 0.4$ & $4.1 \pm 0.4$ & $4.3 \pm 0.5$ \\
\hline B (20) & $2.8 \pm 0.3$ & $4.0 \pm 0.5$ & $4.1 \pm 0.4$ & $4.4 \pm 0.5$ & $4.6 \pm 0.5$ & $4.9 \pm 0.6$ & $5.1 \pm 0.7$ \\
\hline$C(23)$ & $3.9 \pm 1.1$ & $5.0 \pm 0.9$ & $5.1 \pm 0.9$ & $5.1 \pm 0.9$ & $5.3 \pm 0.9$ & $5.4 \pm 0.8$ & $5.5 \pm 0.8$ \\
\hline$D(9)$ & $5.3 \pm 0.7$ & $6.3 \pm 0.5$ & $6.4 \pm 0.6$ & $6.8 \pm 0.6$ & $7.0 \pm 0.7$ & $6.8 \pm 0.4$ & $7.1 \pm 0.3$ \\
\hline \multicolumn{8}{|l|}{ Skin PVR } \\
\hline$A(10)$ & $4.2 \pm 0.5$ & $6.6 \pm 0.9$ & $6.9 \pm 0.9$ & $8.2 \pm 1.3$ & $8.4 \pm 1.0$ & $8.8 \pm 1.0$ & $9.3 \pm 1.4$ \\
\hline B (20) & $5.8 \pm 0.7$ & $8.9 \pm 1.3$ & $9.0 \pm 1.3$ & $10.2 \pm 1.4$ & $10.9 \pm 1.4$ & $10.6 \pm 1.8$ & $11.4 \pm 1.8$ \\
\hline$C(23)$ & $8.7 \pm 2.6$ & $11.2 \pm 2.3$ & $11.8 \pm 2.3$ & $12.0 \pm 2.6$ & $12.2 \pm 2.4$ & $12.1 \pm 2.0$ & $12.3 \pm 2.1$ \\
\hline D (9) & $12.6 \pm 1.9$ & $15.6 \pm 2.0$ & $15.6 \pm 1.7$ & $15.7 \pm 1.7$ & $16.7 \pm 1.1$ & $15.5 \pm 1.7$ & $16.5 \pm 1.5$ \\
\hline \multicolumn{8}{|l|}{ Muscle PVR } \\
\hline$A(10)$ & $4.1 \pm 0.4$ & $5.5 \pm 0.9$ & $5.6 \pm 0.8$ & $6.6 \pm 0.8$ & $6.9 \pm 0.7$ & $7.0 \pm 1.1$ & $8.0 \pm 0.9$ \\
\hline B (20) & $5.4 \pm 0.6$ & $7.4 \pm 1.0$ & $7.5 \pm 0.9$ & $7.7 \pm 0.8$ & $8.2 \pm 0.9$ & $9.3 \pm 1.2$ & $9.2 \pm 1.3$ \\
\hline C (23) & $7.2 \pm 2.0$ & $9.0 \pm 1.9$ & $9.0 \pm 1.7$ & $9.0 \pm 1.3$ & $9.3 \pm 1.6$ & $10.4 \pm 4.1$ & $9.9 \pm 1.5$ \\
\hline $\mathrm{D}(9)$ & $9.2 \pm 1.4$ & $10.8 \pm 0.9$ & $10.9 \pm 1.0$ & $12.1 \pm 1.6$ & $12.3 \pm 1.9$ & $12.3 \pm 0.6$ & $12.5 \pm 0.7$ \\
\hline
\end{tabular}

' Group A, < 29 wk; group B, 30 to 33 wk: group C, 34 to 36 wk: group D, > 37 wk.

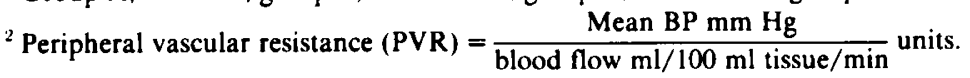

${ }^{3}$ Differences between gestational age groups are signficant for each postnatal day $(P>0.0001)$.

${ }^{4}$ Numbers in parentheses, number of infants.

${ }^{5}$ Mean \pm 1 S.D.

18 infants at weekly intervals during the first 4 wk postnatally. Total blood peripheral flow decreased significantly from wks $I$ to 4 (at $\alpha=0.05 ; F=21.1 ; P<0.0001$ ) (Table 5). This decrement is due to decrease in both the skin and muscle blood flow, but the decrement in skin blood flow was greater than muscle blood flow during the first $3 \mathrm{wk}$. In the fourth wk, the decrement in muscle blood flow was greater than skin blood flow $(P<0.0001)$.

Peripheral vascular resistance continued to change during the first 4 wk postnatally and was found to be directly correlated with increasing postnatal age (coefficient correlations ranging from 0.63 to 0.71 ). SPVR was found to be greater than MPVR with advancing postnatal age.

\section{DISCUSSION}

Plethysmography has been widely used both in adults and in infants for estimation of blood flow in segments of the human extremity (11). In the neonate, the technique has been used to demonstrate blood flow differences in regard to differences in maturity (12) and response to change in state or activity and biochemical and environmental changes $(1-6,12,14,15,18,19$, 21,22 ). However, previous plethysmography methods have their usefulness limited by the difficulties involved in separation of blood flow through the skin and muscle (8). Current widespread use of nonionizing radiant energy in the nurseries, e.g., radiant 


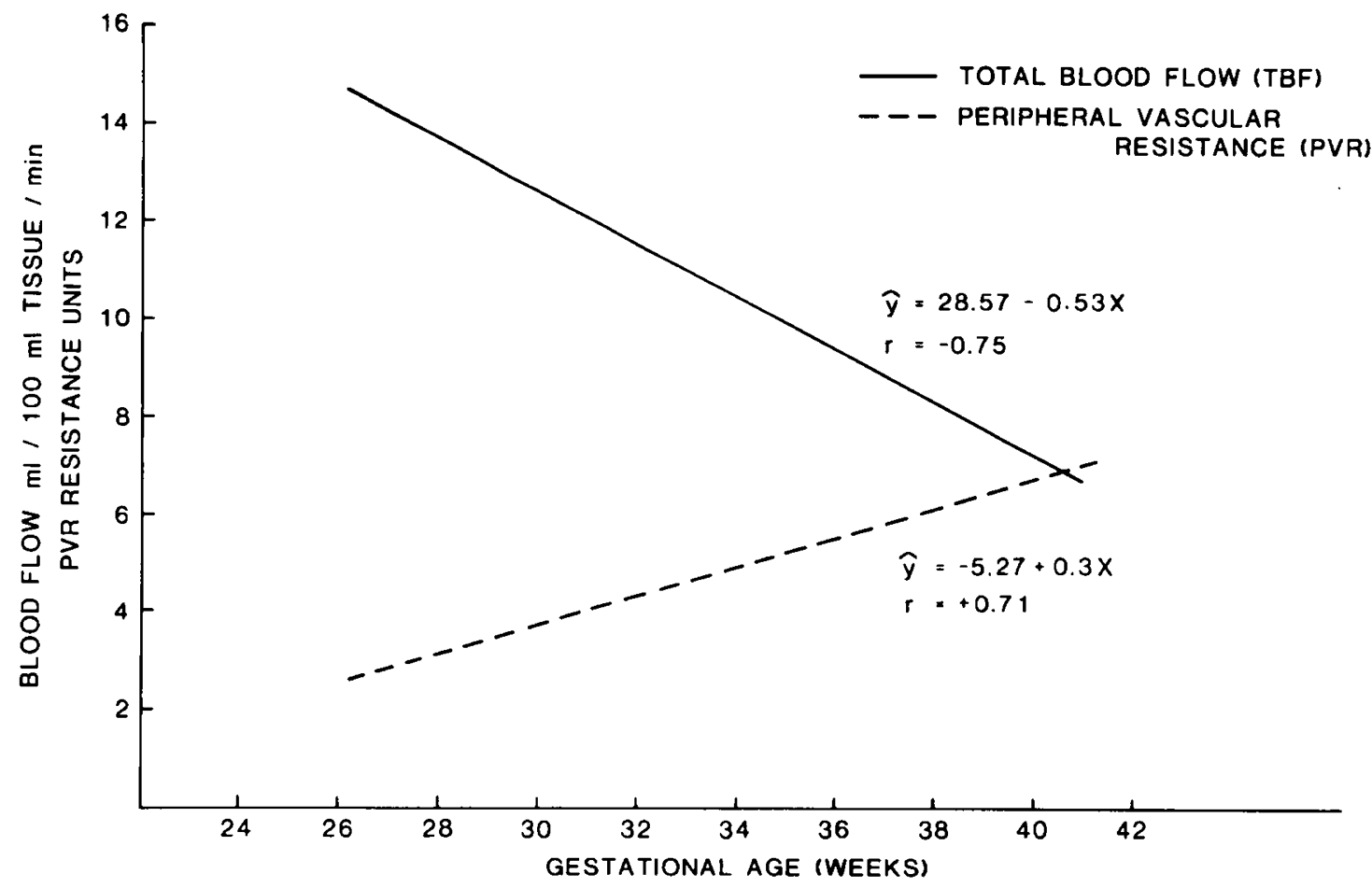

Fig. 1. Illustrates the inverse correlation of TPBF and direct correlation of peripheral vascular resistance with gestational age in 427 measurements taken during the first 7 postnatal days.

Table 5. Sequential changes in peripheral blood flow and peripheral vascular resistance in 18 preterm infants ${ }^{1}$ during the neonatal period

\begin{tabular}{|c|c|c|c|c|c|c|}
\hline \multirow[b]{2}{*}{ wk } & \multicolumn{4}{|c|}{ wk } & \multirow[b]{2}{*}{$F$ ratio } & \multirow[b]{2}{*}{$P$} \\
\hline & 1 & 2 & 3 & 4 & & \\
\hline \multicolumn{7}{|c|}{$\mathrm{BF}^{2}(\mathrm{ml} / 100 \mathrm{ml}$ tissue $/ \mathrm{min})$} \\
\hline Total peripheral BF & $10.6 \pm 1.2^{3}$ & $10.1 \pm 0.9$ & $9.2 \pm 1.0$ & $8.2 \pm 0.7$ & 21.1 & $<0.0001$ \\
\hline Skin BF & $4.7 \pm 0.6$ & $4.3 \pm 0.4$ & $3.8 \pm 0.6$ & $3.4 \pm 0.5$ & 21.4 & $<0.0001$ \\
\hline Muscle BF & $5.9 \pm 0.7$ & $5.7 \pm 0.6$ & $5.4 \pm 0.6$ & $4.8 \pm 0.4$ & 12.5 & $<0.0001$ \\
\hline \multicolumn{7}{|l|}{ PVR } \\
\hline Total PVR & $5.0 \pm 0.7$ & $5.3 \pm 0.6$ & $6.0 \pm 0.7$ & $6.8 \pm 0.7$ & 25.1 & $<0.0001$ \\
\hline Skin PVR & $11.3 \pm 1.7$ & $12.3 \pm 1.4$ & $14.7 \pm 2.6$ & $16.5 \pm 2.8$ & 20.6 & $<0.0001$ \\
\hline Muscle PVR & $9.0 \pm 1.3$ & $9.4 \pm 1.2$ & $10.1 \pm 1.2$ & $11.7 \pm 1.2$ & 17.4 & $<0.0001$ \\
\hline
\end{tabular}

'Mean birth weight, $1450.3 \pm 178.9 \mathrm{~g}$; mean gestational age, $32 \pm 1.9 \mathrm{wk}$.

${ }^{2} \mathrm{BF}$, blood flow; PVR, peripheral vascular resistance

${ }^{3}$ Mean \pm 1 S.D.

heat warmers and phototherapy, focus on the need to have a technique which is capable of separating the skin and muscle blood flow. The electrocapacitance-plethysmograph method has been found to be able to meet this need. As with all plethysmographic studies, careful attention needs to be given to the state of the infant as well as skin temperature to obtain reproducible values. Our own observations indicate that muscular activity such as feeding or crying may be associated with a significant rise in total peripheral blood flow (30 to $250 \%$ ). This rise is primarily due to increase in muscle blood flow which was observed to be between 75 to $360 \%$. However, in most preterm infants, there is a rapid decrease in peripheral blood flow when the infant is quiet or asleep; this state is generally quickly achieved postprandially. The optimal time to obtain recordings for preterm infants had been found to be between 0.5 to $1.5 \mathrm{hr}$ postprandially (21). For more mature infants, this is generally between 1 to $2 \mathrm{hr}$ postprandially. Even then, whenever muscle activity was registered by the instruments, the measurements were interrupted and only resumed after relaxation was achieved (19). These data therefore represent blood flow measurements obtained during a quiescent period in between two active periods associated with hunger and feeding and may not be related to the immediate postprandial "rest state" of the infants.

Changes in body temperature, on the other hand, are associated with change in total peripheral blood flow, but these changes are primarily observed in skin blood flow. Thus a rise of 0.5 to $1^{\circ} \mathrm{C}$ in body temperature was found to cause a three-fold increase in skin blood flow (9). Similar increments in skin blood flow have also been observed when infants were exposed to phototherapy (20). Exposure to phototherapy was found to be associated with a rise of $224 \%$ in skin blood flow compared to a rise of $35 \%$ in muscle blood flow. The differences in the response of muscle and skin blood flow to different stimulus has clinical relevance; for example, a major factor in the increased insensible water losses in infants on phototherapy is largely due to the high increases in skin blood flow $(14,20,21)$. The increased insensible water losses of infants under radiant heat warmers (21) may also be related to changes in skin blood flow and needs to be studied. Although these increases in peripheral blood flow have been noted to be associated with rise in heart rate (20), the effect of these changes on the cardiovascular system, e.g., cardiac output, have not been studied. 
The present study showed that peripheral blood flow in the immature infants is much higher than that in term infants. This is related to the differences in peripheral vascular resistance. Other factors may be due to the general relative decrease in muscle tone as well as to relative hypervascularity in the skin in the more immature infants $(1,2)$. With advancing maturity and postnatal age, the muscle tone increases along with increase in peripheral vascular resistance and a reduction in peripheral blood flow.

\section{REFERENCES AND NOTES}

1. Berg, K., and Celander, O.: Circulatory adaptation in the thermoregulation of full term and premature newborn infants. Acta Paediatr. Scand., 60: 278 (1971).

2. Celander, O.: Blood flow in the foot and calf of the newborn. Acta Pediatr., 49: 488 (1960).

3. Celander, O.: Studies of peripheral circulation. In: D.E. Cassels: The Heart and Circulation in the Newborn and Infant. pp. 98-110 (Grune \& Stratton, New York, 1966).

4. Celander, O., and Marild, K.: Reactive hyperemia in the foot and calf of the newborn infant. Acta. Paediatr. Scand., 51: 544 (1962).

5. Celander, O., Prod'houi, L. S., Frenk, N., and Sigdell, J. E.: Cardiovascular adjustment to acute hypo- and hypervolemia during exchange transfusion in newborn infants. Pediatr. Res., $1: 411$ (1967).

6. Celander, O., and Thunell, G.: "Mercury-in-rubber" strain gauge for measurements of blood pressure and peripheral circulation in newborn infants. Acta Pediatr., 50: 505 (1961).

7. Dubowitz, L., Dubowitz, V., and Goldberg, C.: Clinical assessment of gestational age in the newborn infant. J. Pediatr., 77: 1 (1970).

8. Hensel, H., Rueff, J., and Golenhofen, K.: Human muscle and skin blood flow. Angiology, 6: 190 (1955).

9. Hyman, C., Greeson, T., Clem, M., and Winsor, D.: Capacitance plethysmograph method for separating blood flow in muscle and skin in the human forearm Am. Heart J., 68: 508 (1964).

10. Hyman, C., and Wong. W. H.: Capillary filtration coefficient in the extremities of man in high environment temperatures. Clin. Res., 22: 251 (1968).
11. Hyman, C., and Winsor. T.: History of plethysmorgraphy. J. Cardiovasc. Surg., 2: $506(1961)$.

12. Kidd, L. Levison. H.. Gemmel. P., Aharon. A.. and Swyer, P. R.: Limb blood flow in the normal and sick newborn. Am. J. Dis. Child., /12: 402 (1966)

13. Nie, N. H., Bent. D. H., Hull. C. H., Jenkins. J. G.. and Steinbrenner, K.: Statistical Package for the Social Sciences. Ed. 2 (McGraw-Hill Book Co., New York, 1975).

14. Oh. W. Yao, A. C.. Hanson. J. S., and Lind. J. The effects of phototherapy on peripheral blood flow and insensible water loss in newborn infants. Clin. Res., 20: 283 (1972).

15. Riley, I. D.: Hand and forearm blood flow in full-term and premature infants. Clin. Sci., 13: 317 (1954).

16. Scheffe. H.: The Analysis of Variance. (John Wiley \& Sons, Inc.. New York. 1963).

17. Silverman, W. A.: General considerations, relationship between length, weight. surface area and fetal age. In: Dunham's Premature Infants. Ed. 3. pp. 56-57 (Harper \& Row, Publishers, Inc., New York, 1964).

18. Wallgren, G., Hansen, J. S., and Lind, J.: Quantitative studies of the human neonatal circulation. IV. Observations on the newborn infants' peripheral circulation and plasma expansion during moderate hypovolemia. Acta Pediatr. Scand., 56 (Suppl. 179): 55 (1967).

19. Wong, W. H., Wu, P. Y. K., Kafka, H., Freedman, R. I., and Levan, N. E.: Blood flow and venous distensibility in the upper and lower extremities of newborn infants. Acta Pediatr., 65: 571 (1976).

20. Wu, P. Y. K., and Hodgman, J. E.: Insensible water loss in premature infants: changes with postnatal development and non-ionizing radiant energy. Pediatrics. 54: 704 (1974).

21. Wu. P. Y. K., Wong. W. H.. Hodgman, J. E., and Levan, N.: Changes in blood flow in the skin and muscle with phototherapy. Pediatr. Res., 8: 257 (1974).

22. Yao, A. C., Wallgren, G. C.. Sinha. S. N.. and Lind. J.: Peripheral circulatory response to feeding in the newborn infant. Pediatrics, 47: 378 (1970).

23. This research project was reviewed and approved by the Research and Human Ethics Committee of the Los Angeles County-University of Southern California Medical Center and conducted in accordance with principles of the Declaration of Helskinki.

24. Requests for reprints should be addressed to: Paul Y. K. Wu. M.D., Women's Hospital, Room 919. 1240 N. Mission Road. Los Angeles, CA 90033 (USA)

25. This research was supported in part by a grant from the Birley Foundation.

26. Received for publication August 29, 1979.

27. Accepted for publication March 24, 1980. 